\title{
IMPLEMENTATION OF SOCIALLY RESPONSIBLE BUSINESS TRANSACTIONS IN TRADING COMPANIES
}

\author{
${ }^{1}$ College of Applied Sciences "Lavoslav Ružička" in Vukovar, Vukovar (CROATIA) \\ ${ }^{2}$ College of Applied Sciences "Lavoslav Ružička" in Vukovar, Vukovar (CROATIA) \\ ${ }^{3}$ University of Applied Sciences Baltazar Zaprešić, Zaprešić (CROATIA) \\ Emails:smrvica@vevu.hr;mnedovic@vevu.hr;matej.galic@bak.hr
}

MRVICA MAĐARAC Sandra ${ }^{1}$, NEDOVIĆ Mirjana², GALIĆ Matej

\begin{abstract}
Trade companies are becoming aware of their role in society and the local community.

Socially responsible business transaction means a positive approach to the relationship with the community, its problems and events. It has become recognized among the customers and the company's management. Companies have carried out volunteering and various humanitarian activities to engage themselves in social activities and to increase their reputation towards their customers, suppliers and employees. Factors that have influenced to the development of socially responsible business transactions are: globalization, the transition to a knowledge society, consumer care, civil society activities, environmental problems and other. Trading companies that operate in line with the concept of socially responsible business transactions, when they implement this type of business, they can achieve a numerous benefit, from strengthening of the corporate image, and from competitiveness to the environmental awareness. Socially responsible business transaction also maintains cooperation between businesses, civil society and public administration and as such creates a positive image of social responsibility and contributes to the development of the local community. For the purpose of this paper a research was conducted on a representative sample of trading companies with the aim of gaining insight whether such companies do promote socially responsible business transactions and what kind of activities in such form these companies use.
\end{abstract}

Keywords: socially responsible business transaction, trade companies, positive approach, humanitarian activities, research

JEL: M14

UDC: 658:339

005.35

COBISS.SR-ID 28652553

\section{Introduction}

The very concept of corporate social responsibility involves the contribution of the company to the community and the quality of life within it, alongside with the ethical, legal and economic responsibility of doing business. Corporate social responsibility in management attracts customers because this concept creates a positive image of the overall company's business. In this way the efforts of the company are aimed to improve the society and the community in which it operates. By using the socially responsible business, the concerns and activities for the wider community become a part of the business strategy of the 
company, and it also provides an opportunity for collaboration between businesses and nonprofit organizations. Orientation to the consumer's, the opening of new markets and the impact of non-profit organizations influence the development of this conception of business.

In the paper, research has been conducted on 32 trading companies in Republic of Croatia with the aim of finding out how much they carry out socially responsible business activities, what activities they carry out and whether they think that socially responsible business activities have a positive impact on the business and image of the company. There are quoted examples of the concept of the corporate social responsibility in the business practices of some companies (Coca Cola HBC, Konzum JSC, and Ericsson Nikola Tesla JSC) that are cited.

\section{The socially responsible business concept}

The Corporate Social Responsibility (CSR) is the concept of how company behaves across the entire spectrum of its business with regard to the wider community and aligns its behaviour on the market with the needs of the company.

More recently, it has increasingly been written about importance of a company as a socially responsible subject, so the socially responsible behaviour has become as a part of business strategies, because in this way a greater competitiveness and better perception of the company in public is sought to be reached. Corporate social responsibility not only applies to the large multinational businesses, but is also increasingly concerned with the importance of including this concept of business alongside with the small and medium-sized enterprises.

Any business entity that cares about how it has been perceived by the public, maintain serious approach to this concept because it wants to put on a positive image of themselves on the general public.

The goal of CSR can also be sensitivity towards the wider social community, in such a way that part of the profitability of the company is reflected to the improvement of the quality of life of entities outside the company.

In the literature, there are numerous definitions and explanations of what CSR is, but it can be observed that the starting point for defining is to shape the entire management of a business entity in a way that contributes to the benefit of the wider community.

Definitions of corporate social responsibility have evolved through its evolution, so the term is now used interchangeably with the terms of "social responsibility", "sustainable development" and "corporate citizenship" [1].

Social responsibility represents a concept in which a business entity voluntarily decides to contribute to a better society and a cleaner environment when interacting with other stakeholders [2]. Furthermore, it is quite certain that a business entity primarily needs to meet its basic objectives and justify its stability on the market and as a result justify its purpose of existence, and then to satisfy the expectations not only of its internal but also ones originated from the external environment.

In favour of this way of thinking it is determined that there exists a continuous strive for a better positioning of the company and also to maximize its profits, and also the businesssubjects that are improving businesses, and apart from improving their position they also contribute to the overall wealth and well-being of a society as a whole [3].

The whole CSR practice began as a way of managing risks in large multinational companies, which were exposed to attacks due to their environmental or employee policies.

As a result, they have adopted proactive behaviour, that is, practices that were pre-declared (and could be verifiable) as sensitive to the environment and the communities in which they operate. The essence of CSR business making is that it goes above and beyond of what the law prescribes in relation to the environment and society. Another important determinant is 
the establishment of dialogue and genuine collaboration between businesses and organizations in the non-profit sector (CSR Good Croatia) [4].

Today, it is increasingly stressed that not only understanding the importance of socially responsible behaviour is important, but also managing socially responsible businesses, which actually enters the field of management and can no longer be left to mere chance.

The group of authors also talks about socially responsible behaviour limits, explaining that all types of organizations, public and private, have their mission, strategy, policy and set goals. On the other hand, these organizations have limited resources to achieve these goals.

Moreover, organizations have a field of activities that are more or less defined and it is not possible to pretend for them to act outside their own responsibilities [5].

As a result of a new way of thinking about the work and connection of business subjects with the community and measuring inclusion, the Croatian Chamber of Commerce annually invites representatives of the small, medium, large and public businesses to participate in the questionnaire. Questionnaires were published individually for small, large and medium-sized enterprises and public companies. Businesses entities that, by certain criteria, operated positively in terms of business performance and, therefore the socially responsible behaviour index is shown. The completion of the CSR questionnaire can be accessed by any interested business entity that has previously met certain criteria. The questionnaire consists of a number of questions that are related to socially responsible behaviour. Below are outlined the main questions for the small business. The main questions can consist of a series of sub questions (Table 1) when the assessment of socially responsible practices is undertaken.

Table 1. Example of a CSR questionnaire for the small businesses

\begin{tabular}{|l|l|}
\hline 1 & General company information \\
\hline 2 & Company's focus on economic sustainability \\
\hline 3 & $\begin{array}{l}\text { Inclusion of corporate social responsibility (CSR) and sustainable development } \\
\text { (SD) in the business strategy }\end{array}$ \\
\hline 4 & Responsible policies and practices in the work environment \\
\hline 5 & Responsible environmental management policies and practices \\
\hline 6 & Corporate social responsibility in market relations \\
\hline 7 & Socially responsible relationships with the community \\
\hline 8 & Responsible policies for diversity and protection of human rights \\
\hline
\end{tabular}

Source: [12]

It is quite certain that business entities can no longer be focused exclusively on the achievement of their own internally set goals, as well as the realization that a successful business result is no longer the only evaluation criterion. The existence of questionnaires, monitoring and visibility of the CSR index represents another business model that encourages market players to reflect on and satisfy the wider interests of the community in a way that profits are made in a socially responsible way.

Socially responsible behaviour in today's business environment is increasingly important, especially after the European Commission has defined what are corporate social behaviour, as well as the set guidelines and principles for the implementation of CSR. Businesses are monitored and evaluated to what extent they behave socially responsible. The European Union, by its Directive (2014/95/EU), defines the rules for large companies, their ways of publishing concrete information on social and environmental impacts. The directives, which have been consistently implemented by the Member States of the European Union into national law, came into force in 2017 - such as the case of Germany. Following the publication of conceptual and empirical research that resulted from CSR reporting practices, CSR has attracted the attention of researchers, practitioners and policy maker's in various disciplines. 


\section{Types of Corporate social responsibility}

From the literature it can be distinguished several types of CSR and Buble [6] distinguishes the four types of CSR: economic, legal, ethical and community responsibility. Economic responsibility arises from the very purpose of a being a business entity (it refers to making a profit and satisfying a consumer's need). In this context, the short- and long-term goals are met. The long-term goals are to achieve a competitive advantage, which is considered as the economic responsibility of the business entity.

The legal responsibility of the business entity is focused on the laws, that is, their compliance by the state. By regulations are stipulated the relations of general social interest.

In the case of non-compliance with the law the sanctions are imposed, and are mostly often expressed in fines. Furthermore, in the case of the non-compliance with the legal regulations, members of the management are subject to sanctions, because their task is to monitor the legality of the business entity. The ethical responsibility of the business entity is not prescribed, but it is implied. The ethics of the business is assessed in a way when compares wrongdoing versus correct behaviour. Businesses very often have a code of ethical conduct that defines the rules of conduct [3]. Figure 1 shows the types and hierarchy of social responsibility.

The economic responsibility is presented at the first level of the pyramid as the basic economic unit of society, followed by the legal responsibility, ethical responsibility and discretionary responsibility that is solely conceived on a voluntary basis by a business entity.

Through the presented levels of socially responsible behaviour, a business entity should develop each of the presented levels in order to contribute to the benefit of the wider community, to be responsible to it, and to be perceived by the general public as a socially responsible and as desirable actor in the market.

On this way of thinking and implementing of all kinds of CSR contributes to the development of the community as a whole.

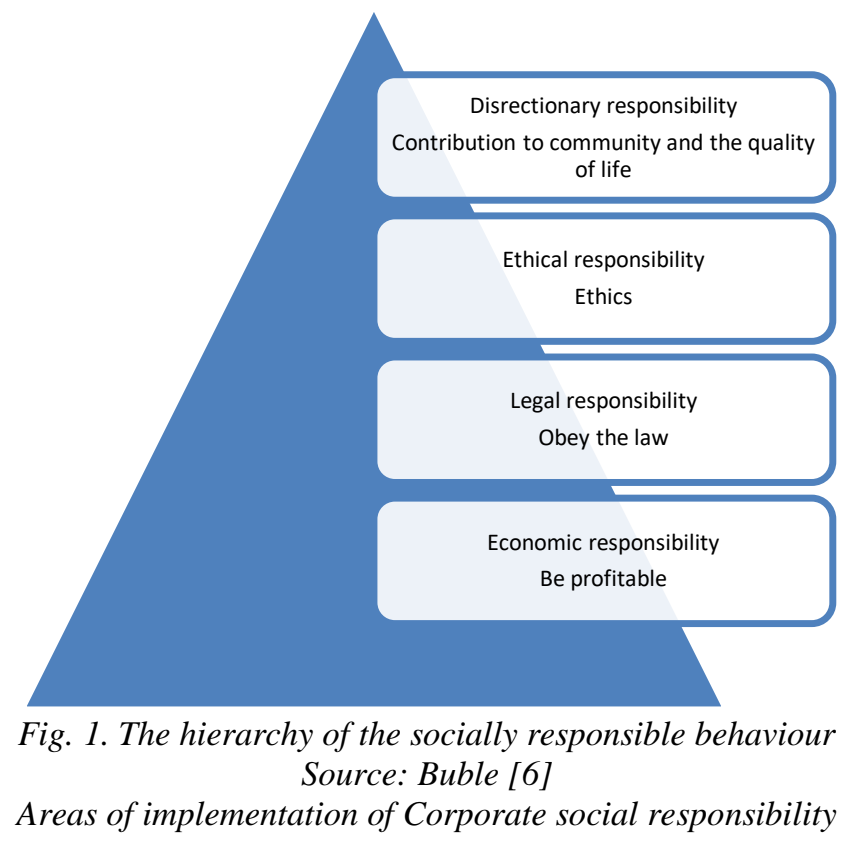

The main elements of corporate social responsibility are ethical business, responsibility to employees, contribution to society and social issues such as ecology, safety, health, education and the like. This type of business is achieved through the development and implementation of business practices and company activities with the intention or aim of improving the well- 
being of the community and the society in which the organization operates, therefore improving the quality of life of employees and creating a positive image of the company in public [7]. Corporate Social Responsibility is becoming part of the corporate competition among the companies. This is demonstrated by today's businesses; whose higher profits are not their only priority. Companies have realized that it is important for their image that they are socially responsible, and at the same time it is the best way to contribute to society in some way. Nowadays we often hear phrase how changes must be implemented and how everyone should be socially responsible, but work should speak for itself. There are a large number of companies in Croatia that implement corporate social responsibility, such as Ericsson Nikola Tesla, Konzum, Jamnica, Coca Cola, Generali Security, AD Plastik, Ina, Janaf and many others. In the following, it will be outlined the areas of corporate social responsibility in some of these aforementioned companies.

From 2010 until 2017 Coca-Cola HBC Croatia has reduced the water consumption to $11 \%$ and amount of waste by $50 \%$. Direct discharge of carbon dioxide is reduced by $60 \%$, and then discharge part of carbon dioxide in the value chain was $48 \%$. Total energy consumption per litre of produced beverage in the bottling plant has been reduced by $15 \%$ during the last ten years, all of which are seen as concrete indicators of the contribution to society through ecology. Furthermore, Coca-Cola Croatia is also one of the most desirable employers in Croatia that attracts and retains the best employees through a stimulating work environment and a clear and competitive remuneration system, therefore demonstrating responsibility towards their employees. Coca-Cola has a reputation as one of the most socially responsible companies in the world, and thus in Croatia, because they use social engagement as a means of evaluating work. They are often part of a public-private partnerships that aim to further motivate other project partners and, as one of the best examples of this type of partnership is illumination of the Osijek pedestrian bridge as one of the city's trademark symbols, making the city of Osijek even more beautiful and pride to its citizens [8]. In Konzum they understand the principles of sustainable financial performance and success, so they take care of socially responsible business, where environmental protection at the local, regional and national levels is a key consideration. In addition to environmental standards and procedures that all employees in their day-to-day operations need to be familiar with and annual controls on compliance with these standards, Konzum has taken a step further by joining the Green City project, an initiative to sensitize the Croatian public to problems of the environment protection, with particular emphasis to the education of the young people about environmental issues. Children and the youngest have always been the focus of Konzum's socially responsible business, which is best seen by the project "Let's bring children back to the playgrounds". Several years ago, as part of this project there were opened 20 playgrounds, what represent an indicator that the Konzum has been making for the benefit of the community in which it operates [9]. Most companies invest in society by means of repairing the damage that has been done by the others through their irresponsible businesses and they educate people about a healthier lifestyle that is beneficial to society, and Ericsson's priority is investing in the development of technologies that will help society to avoid environmental pollution and other harmful activities which are inflicted by people. In Ericcson believe that investment in scientific development gives people the economic, social and environmental edge. Ericsson has developed a sustainability policy which have its fundamental basis on the usage of product life cycle methodology to determine their significant environmental impacts and assess the environmental impact of ICTs on environment, thus reducing the impact of their business to the environment and to take precautionary measures with regards to the environmental challenges, and also to apply design principles that are acceptable for the environment to ensure continuous improvement in environmental protection from the perspective of the life cycle of products from Ericsson's portfolio etc. [10]. From all the above 
said, it can be concluded that there are four areas of corporate social responsibility, namely the market, the working environment, the social community and the environment. Corporate Social Responsibility should provide customers with quality products and services tailored to their requirements, to treat customers justly in all aspects, to make efforts to maintain and enhance customer health and safety of products and services, to ensure respect for human dignity in products offered, placement and advertising, respecting cultural habits and customer identities. In addition to selling, one's own products, purchasing is also important to the company, since the products and services of the suppliers directly affect the quality of the company's products, and it is extremely important to have a stable supplier that delivers a fair number of inputs needed to meet the needs of the end user. Corporate Social Responsibility Businesses are based on a mutually build relationships with suppliers and subcontractors in exchange for quality of delivered products and reliability in delivery, to share information's with suppliers for them to include them in the planning process, pay suppliers on time, encourage and remain loyal to suppliers and subcontractors, who promote agreed corporate social responsibilities and subcontractors which in their businesses promote socially agreed behaviour [11].

\section{Research methodology and the results}

Survey data were collected using the survey questionnaires and it was conducted in November and December of 2019. In the research participated the representatives of middle and upper management from 32 trade companies from the Republic of Croatia. The questionnaire as a survey instrument contain 10 questions related to the knowledge of the concept of corporate social responsibility, its implementation in the company, the actions of socially responsible business used and the influence of corporate social responsibility of trading companies on the company business, and so its acquired image in the public. Before starting the survey, the respondents were become familiar with the research and the subject of the research. The sample is appropriate because only representatives of trading companies were targeted in the sample. In accordance with the set theoretical-methodological approach and the stated problematic, several hypotheses can be carried out:

$H_{1}$ - Trading companies carry out CSR activities through humanitarian actions and donations.

$\mathrm{H}_{2}$ - Trade companies participate in the organization of sports events and the promotion of sports.

$H_{3}$ - Respondents consider that CSR has a positive impact on the business of the company and the image of the company in public.

The survey involved 15\% of micro-trading enterprises (with less than 10 employees), 19\% of small-scale commercial enterprises (with less than 50 employees), $25 \%$ of medium-sized commercial enterprises (with less than 250 employees) and $41 \%$ of large enterprises (with more of 250 employees). With the concept of corporate social responsibility is familiar $91 \%$ of respondents, and $72 \%$ of respondents from trade companies' representatives have in their document's items on sustainable responsibility (e.g., in their vision, development strategy in the rulebooks). Total of 50\% of respondents have employees in their company who were put in charge of conducting socially responsible business, but $72 \%$ of respondents do not report to the media about conducting socially responsible business in their company. Those $72 \%$ of respondents did not support a financial donation in 2019, and 54\% of respondents did not support a non-financial donation during the same year (donations in the form of products, equipment, voluntary work of employees etc.).

In 2019, the largest number of respondents participated in humanitarian actions (53\%) and donations (to hospitals, associations, homes) (53\%). In organizing of the sports events and for 
the sports promotion in 2019 participated $51 \%$ of those polled. Among other CSR activities, respondents participated in: eco-initiatives (31\%), scholarships for pupils and students (25\%), social education (19\%), donations and actions for preserving and care of animals (9\%), and participation in financing construction of buildings for the social benefits (playgrounds, promenades, kindergartens etc.) (6\%). Among other activities, the respondents as representatives of trading companies did not mention of any other of CSR activities that were carried out in their company. From total number of respondents, $85 \%$ of them believe that corporate social responsibility has a positive impact on corporate business and also $87 \%$ of respondents believe that corporate social responsibility has a positive impact on corporate image in the public.

\section{Conclusion}

Corporate Social Responsibility (CSR) is one of the components of modern business.

Because they form an integral part of the fabric of the society in which they work, in addition for consideration for positive business and revenues, businesses need to contribute to the community and quality of life. The results of the research conducted for the purpose of this paper indicate the positive impact of trading companies on the concept of corporate social responsibility. Half of the companies that participated in the survey have employees responsible for conducting corporate social responsibility, and more than half of the researched companies have CSR items implemented in their documents. Companies are more supportive of non-financial donations (such as donations in products, equipment, and voluntary work of their employees, etc.). The surveyed companies participated in humanitarian actions in 2019 (53\% of them) and made donations to hospitals, associations or homes $(53 \%)$, thus confirming $H_{l}$ hypotheses $\left(\mathrm{H}_{1}-\right.$ Trade companies carry out CSR activities through humanitarian aid actions and donations), $51 \%$ of enterprises participated in the organization of sports events and the promotion of sport in 2019, confirming the $\mathrm{H}_{2}$ hypotheses $\left(\mathrm{H}_{2}-\right.$ Trading companies participate in the organization of sports events and the promotion of sports. Among the other CSR activities, the trading companies that participated in the research carried out ecological initiatives, scholarships for pupils and students, they held educations of social importance, made donations and care for animals, they participated in financing the construction of facilities for social benefits (such as playgrounds, promenades, kindergartners etc.). Respondents believe that CSR has a positive impact on the company's business (85\%) and the public company's image $(87 \%)$, thus confirming the hypothesis $\mathrm{H}_{3}$ (Respondents consider that CSR has a positive influence on the company's business and image of the company in public) From all of the above said it follows that corporate social responsibility is accepted in the practice and businesses of trading companies in the Republic of Croatia.

\section{REFERENCES}

[1] Vrdoljak Raguž, I. \& Hazdovac, K., (2014), Corporate Social Responsibility and Croatian Economic Practice, Oeconomica Jadertina, Vol. 4, No. 1., pp. 40-58.

[2] Pavić-Rogošić, L., (2012), Socially responsible behaviour, Zagreb: Reflection.

[3] Grbac, B., Dlačić, J. \& First, I., (2008), Marketing Trends, Rijeka: University of Rijeka, Faculty of Economics.

[4] CSR Good Croatia, what is Corporate Social Responsibility? [available at: http://responsible.hr/aboutcsr-in-expert/what-is-corporate-responsible-business/, [accessed 22.02.2020.]

[5] De Los Angeles Gil Estallo, M., Ginger De La Fuente F. \& Griful-Miquela, F., (2007), The Importance of Corporate Social Responsibility and Its Limits, available at: https://doiorg.ezproxy.nsk.hr/10.1007/s11294-007-9095-x, [accessed 30.01.2020.] 
[6] Buble, M., (2000), Management, Split: Faculty of Economics in Split.

[7] Kotler, Ph. \& Lee, N., (2005), Corporate Social Responsibility, Zagreb: MEP Consult Ltd.

[8] Coca-Cola Hrvatska, available at: https://hr.coca-colahellenic.com/hr/media/news/leader-insustainable-and-socially-responsible-business/, [accessed: 10.02.2020.]

[9] Konzum, available at: www.konzum.hr, [accessed 02.02.2020.]

[10] Ericson Nikola Tesla d.d., available at: https://www.ericsson.hr/documents/20181/21690/Sustainability Policy.pdf/a1b2b107-cb96-4896-8600-94a1de06a0d7, 2/10/2020, [accessed: 11.02.2020.]

[11] Vujić, V., Ivaniš, M. \& Bojić, B., (2012), Business Ethics and Multiculture, Rijeka: University of Rijeka - Faculty of Opatija.

[12] Croatian Chamber of Economy (2020), About the CSR index project (nd)., available at: https://dop.hgk.hr/, [accessed 22.01.2020.]

\section{Article history:}

Received 3 November 2020

Accepted 8 December 2020 